Arja Ropo, Elina I. Mäkinen \& Inka Seppä

Faculty of Management and Business

Tampere University

\title{
Online company blogs as narrations of plural leadership
}

\begin{abstract}
Purpose - The purpose of this study is to examine how companies that characterize their leadership style as plural, shared, or distributed narrate their actions and practices in online blog texts.

Design/methodology/approach - The data consist of online blog texts published by seven Finnish IT-companies. The analytical strategy draws on both thematic and structural approach to narrative analysis. The blog texts were analysed thematically to uncover different aspects of plural leadership. The analysis revealed a narrative pattern consisting of three categories that explain why and how companies implemented plural leadership.

Findings - The first category in the narrative pattern describes the motivation for engaging in plural leadership. The second category explains how the companies broke down existing hierarchies in order to create new flexible work roles. The third category describes how the organisations sought to create a communal culture and a strong sense of trust using symbols, material objects, and spaces.

Research limitation/implications - The study contributes to leadership research that emphasizes post-heroic leadership conceptualizations. The narrative pattern provides future empirical studies a framework for analysing plural leadership practices in different organisational settings. While this study sheds light on the ways in which organisations and their leadership practices can be investigated using online data, traditional organisational ethnographies can make a further contribution to this line of research.

Practical implications - Implementing plural leadership in organisations can lead to informal power plays. Attention should be paid on to how plural leadership evolves in flat hierarchies and promote community building.

Originality/value - Company webpages have rich information on how companies operate and perceive themselves. They provide yet another window for observing organisational activities. This study makes a novel contribution to how plural leadership is practiced and conceptualized in online blog texts.
\end{abstract}

Keywords Plural leadership, Leadership practices, Narrative analysis, Narrative pattern, Digital narration

Paper type Conceptual paper

\section{Introduction}

Webpages and social media have become a crucial point of communication between organisations and their internal and external audiences (Powell et al., 2016; Leonardi and Vaast, 2017). The 
webpages of organisations are not only used to inform audiences, but also to construct reality and organisational practices. They are representations and narratives of what organisations are about and what they hope to achieve (Powell et al., 2016).

Given that webpages provide us with a tremendous amount of detailed and up-to-date information about how companies operate and how they perceive themselves, they also shed light on their leadership practices. Capturing how companies practice leadership is an important research topic, because companies are exploring how to move away from traditional, heroic, and top-down conceptions of leadership that are often seen as damaging to innovation and creativity. Leadership researchers have recognized the need to consider leadership as everyday practices shared throughout the organisation rather than as actions of a few leaders at the top-level of the organisation (Crevani et al., 2010; Denis et al., 2012; Raelin, 2016a, 2016b). This speaks to the need to understand how actors in different organisational roles conceive and practice leadership in a digital environment.

Taken together, we see online company blogs as advantageous data for analysing how modes of plural leadership are actualized in organisations. By focusing on companies that explicitly claim to pursue the logic of plural leadership, our study builds on an emerging stream of research that contends that leadership is no more a monopoly of a few, but is collectively constructed as a plural activity in everyday practices (Crevani et al., 2010; Denis et al., 2012; Raelin, 2016a, b; Sergi, 2016). Furthermore, leadership is considered to occur, not only in relations between people, but also in human-material relations (Hawkins, 2015; Ropo and Salovaara, 2018; Ropo et al., 2013). The increasing materiality in organisations — such as IT-technology, infrastructure, office space, and documents - has been shown to affect organising and leadership (Carlile et al., 2013; Oborn et al., 2013; Orlikowski and Scott, 2008). Therefore, developing a thorough understanding of plural 
leadership practices calls for an empirical investigation that considers everyday organisational practices in human-material relations.

In this article, we study how information technology companies engaged in knowledge-intensive and creative teamwork characterize their leadership practices in online blog texts. For the empirical analysis, we selected companies that have publicized to their internal and external audiences (e.g., media interactions, website, recruitment) that they rely on plural, shared, or distributed leadership (different terms were used). These digital narrations of plural leadership provide a window for exploring a rarely studied empirical phenomenon: how different organisational members construct plural leadership practices. We analysed 89 online blog texts that had been published by seven Finnish IT-companies in the Spring and Summer of 2017. Our analysis focused on how the blogs described the plural leadership phenomenon, how it appeared in company activities, events, and ways of being.

Our findings demonstrate that narrations of plural leadership practices are as varied as the different lines of research on the phenomenon. Yet, we were able to identify a narrative pattern of three categories for plural leadership practices that provide future empirical studies a useful framework for making sense of plural leadership in different organisational settings. The three categories were 1) responding to an unpredictable environment, 2) new organisational roles, and 3) community building.

Our study contributes to the recent leadership research that emphasizes post-heroic leadership conceptualizations. In particular, our study provides empirical insights into how organisations narrate their practice of plural leadership in human-material relations, which is a rather scarcely researched topic. Methodologically, our study builds on reality construction and narration that takes place virtually in company blogs. 
The article is structured as follows. First, we discuss prior literate on plural leadership and the role of human-material relations in this line of scholarship. Next, we present our data and explain how they were collected and analysed. Turning to the empirical analysis, we demonstrate the narrative pattern that describes the logic behind how plural leadership practices were implemented. We conclude by discussing the broader significance of these findings in relation to earlier literature on plural leadership and their implications for practice and further research.

\section{Plurality of leadership as an emerging practice}

Due to changes in ways of working and contexts of work, scholars have sought to identify new ways of practising and conceiving leadership, which has enlivened discussions among leadership scholars and practitioners. Relatedly, leadership research has witnessed an ontological shift from leadercentric to post-heroic approaches during the past decade (Avolio et al., 2009; Crevani et al., 2007, 2010). This line of research emphasizes "the relational, collectivist and non-authoritarian nature of leadership practices in contemporary organisations-opposing against unreflective mainstream perspectives that sustain heroic, individualist, and authoritarian leadership norms" (Crevani et al., 2010, p. 78). There are several post-heroic views of leadership, such as distributed (Gronn, 2002), shared (Pearce and Conger, 2003), and relational leadership (Fairhurst and Grant, 2010; Hosking, 2007; Uhl-Bien, 2006), which all underline, granted with different historical roots and nuances, leadership as a collaborative action rather than as a monopoly of a few in organisational hierarchy.

Denis et al. (2012) used the term "leadership in the plural” to describe leadership theories that examine "leadership not as a property of individuals and their behaviours, but as a collective phenomenon that is distributed or shared among different people, potentially fluid, and constructed in interaction” (p. 212). They identified four different forms of plural leadership: sharing leadership functions in teams, pooling leadership in dyads, triads, or other constellations on the top of an 
organisation, spreading leadership across organisational levels, and producing leadership in emerging interactions in mundane practices and situational contexts (see also Carroll et al., 2008; Raelin, 2011). The first three forms—sharing, pooling and spreading leadership—consider leadership as a function and as specific tasks that are shared among multiple actors. The forth form of plural leadership holds a different view: leadership is as an emerging process that occurs in interactions among people and their environment. During this process, actors negotiate the direction and course of action collaboratively (Crevani and Endrissat, 2016). Our study follows the forth form of plural leadership understood as an emergent property of relations (Denis et al., 2012, p. 215).

This view has been characterized as a leadership-as-practice stream (Carroll et al., 2008; Raelin, 2014, 2016a, b) that emphasizes "non-deliberative collective action emerging from mutual, embodied, situated patterns in the moment and over time among those engaged in the practice” (Raelin, 2014, p. 5). Crevani and Endrissat (2016) pointed out that producing direction and setting the course of action are key leadership functions in moment-by-moment micro-interactions. The LAP (leadership-as-practice) literature distinguishes between practices and practice. "Practices” refer to routinized actions or patterns of action through which the members of a community develop and share social knowledge, whereas "practice" is an emergent assemblage of practices without having identifiable factors, levels, or actors. This suggests that practice is a holistic process of becoming without clear boundaries (Crevani and Endrissat, 2016, p. 43). As such, it is challenging to study empirically (Kempster et al., 2016). Our study focuses mainly on “practices”, but the narrative pattern we identified implies a "practice”, a flow of emergent practices and relations.

The ontological understanding of leadership as an emerging process without clear leader and follower relationships helps explain some of the well-known leaderless grassroots movements. Think of the Occupy movement and Arab spring uprisings (Sutherland et al., 2014) as "leaderful” acting by 
organisational members (Mabey and Freeman, 2010, p. 513; Raelin, 2003) or Internet mobilization and the advancement of collectives in online gaming communities (Margetts et al., 2013). Eslen-Ziya and Erhart (2015) described the Gezi Park protests in Turkey as exemplifying plural, even leaderless, leadership through the material production of leadership through t-shirts, posters, and songs, as well as the use of public spaces like streets, mosques, and squares (p. 478). As noted by Carroll (2016), Hawkins (2015), and Sergi (2016), material objects and artefacts, such as technology, documents, and physical spaces, actively intervene in the unfolding of leadership action (Carroll, 2016; Hawkins, 2015; Sergi, 2016). To develop this idea further, we will next discuss recent literature on the relationship between materiality and leadership.

\section{Leadership in human-material relations}

After decades of linguistics, discourse, and cultural studies in organisational research, scholars have engaged with materiality in organisations leading to what many call the "material turn" in organisation studies (Barad, 2003; Carlile et al., 2013; Dale, 2005; Orlikowski, 2007). The way organisational members interact with materiality has been studied, for instance, in connection to Xerox-machines (Humphries and Smith, 2014; Orr, 1995), smart phones (Orlikowski, 2007), numbers leading to strategic decision-making (Denis et al., 2006), digital pictures (Dourish and Mazmanian, 2013), and organisational space (e.g., Ropo et al., 2015; Taylor and Spicer, 2007; Van Marrewijk and Yanow, 2010).

Quite recently, materiality began to influence scholarship in the leadership field as well. Materiality has been typically understood as material bodies of leaders, their physical presence, bodily performance, or gestures (see Ropo and Salovaara 2018 for a broader discussion). Oborn et al. (2013) considered materiality somewhat differently and stated: “material entities are considered as defining components of leadership; rather than acting as backdrops to practice, datasets, scanners, emergency 
room protocols, videos, and PowerPoint slides configured the relationships among social actors” (p. 268). Hawkins (2015) acknowledged the lack of "thing-ness" in leadership research and studied various material aspects of leadership in the British Royal Navy shore establishment. Ropo et al. (2013; 2015) and Ropo and Salovaara (2018) have undertaken a stream of research to study how physical spaces shape and construct leadership in workplace settings.

The increased interest in materiality in leadership and organizing is connected to the ways in which various forms of technology—computers, Internet, and software—are at the centre of people's lives both at work and outside of work. Human interactions increasingly take place through technological gadgets. As a result, appointed leaders and managers do not have the same kind of a role in producing leadership as they used to. Especially in knowledge-intensive organisations engaged in creative teamwork, leadership tends to be a collective action that occurs in everyday interactions, often through technologically enforced devices and practices (e.g., company blogs, Intranet).

\section{Methodological approach: Digital narrations of leadership}

In modern organisations, individuals participate in organisational activities both in online and offline contexts. Because of this, Akemu and Abelnour (2018) recently argued that to achieve authenticity and multivocality in organisational ethnographies requires researchers to take into account both contexts in data collection. Other organisational researchers have similarly noted that organisations have a digital footprint that consists, for example, of their webpages, blog texts, and online communication channels, which need to be considered in organisational research (Murthy, 2013; Powell et al., 2016; Leonardi and Vaast, 2017). Relatedly, researchers have, for instance, examined how firms interact with communities of consumers on Facebook (e.g., Slobin and Cherkasky, 2010; Mart, 2011; Lin and Lu, 2011). 
Powell et al. (2016, p. 102) focused on webpages and described them as "a form of representation" and "a type of narrative". As such, organisations' presence on the web has also transformed the presentation of organisational narratives. As webpages contain detailed information produced by different organisational members, they provide researchers rich data on organisations' goals, values, and norms. Through organisational narratives we can develop a sophisticated understanding of working lives (Humphreys and Brown, 2002a; Humphreys and Brown, 2002b). Organisational narratives shed light on the members' degree of familiarity with the dominant organisational stories and their identification with the organisation's values and norms (McWhinney, 1984).

In this study, we utilize both online data and narrative research and examine how companies that characterize their leadership practices as plural, shared, or distributed narrate their actions—activities, events, and ways of being-in company blog texts. We analysed 89 online blog texts from seven Finnish IT-companies that openly identified themselves as organisations that rely on plural leadership. The companies had started after the 2000s and they were growing rapidly. All of them engaged with knowledge-intensive and creative work. Six out of the seven companies operated globally, which meant that many of their employees were non-Finnish and that English was the working language. As employees at different organisational levels wrote the blog texts we analysed, they provide a wide lens for understanding the chosen companies. Altogether, the data comprised of 298 pages of text written by 74 blog writers.

To understand the content of the digital organisational narrations, we analysed the blogs thematically to uncover different aspects of the broad phenomenon of plural leadership. We conducted a thematic analysis of the online blog texts that was motivated by the plural leadership literature. While the study is explorative in many ways, it is not purely inductive (Glaser and Strauss, 1967). We developed a 
coding scheme that aligned with prior research on plural leadership, but was also open-ended so that it could take into consideration new and unexplored understanding of plural leadership practices.

The analysis of the blog texts consisted of two stages: initial and focused coding (Lofland and Lofland, 1995). During the initial coding stage, we examined the blog texts looking for evidence for different kinds of practices that could contribute to plural leadership. Before moving on to focused coding, we reviewed prior research on plural leadership in order to develop an understanding of what was already known and what the blog texts were revealing about plural leadership. After this analytical step, we arrived at a coding scheme that we used for focused coding of the entire dataset. While the last author collected the data, all authors were involved in the analysis of the blog texts.

According to Riessman (2008), in narrative research the aim of thematic analysis is not to fracture the data, but to follow the logic of the empirical case. In line with this idea, the thematic analysis of the online blog texts allowed us to identify a narrative pattern, which explains why and how the organisations in question implemented plural leadership. Therefore, our analysis draws on both thematic and structural approaches to narrative analysis (Riessman, 2008).

The narrative pattern we identified consists of three categories that provide a framework for analysing plural leadership in different organisational settings. The first category describes what the motivation was for the IT-companies to engage in plural leadership. The second category explains how the companies broke down existing hierarchies in order to create the flexible work roles they thought they needed for managing unpredictability. The third category describes how the organisations sought to create a communal culture using symbols, material objects, and spaces. 
Next, we present the logic of our empirical case, meaning the narrative pattern with the three categories. Due to the limited space and lengthy quotes, for each category we first present a longer narration followed by shorter data extracts.

\section{Responding to an unpredictable environment: Playing with the unknown}

"I won't lie to you; I don't think we can prevent uncertainty. But we have got it all wrong in the first place. Not having a chain of command can actually reduce riskiness. The key to functioning properly is learning from actions. This is where an approach called build-measurelearn comes in handy. The approach pushes you to get rid of long-term planning and use experiments as a tool for validating hunches and expectations. The thought behind this is that the only way to validate whether something works or not is experimenting-because, as we have already noticed, complexity cannot be predicted."

In the digital narrations of plural leadership, all of the organisations saw plural leadership as an effective strategy for responding to an unpredictable business environment. As the managerial level informant, who wrote the previous long narration, noted, "Not having a chain of command can actually reduce riskiness". While the companies did not think they could prevent uncertainty altogether, plural leadership was seen as a tool for managing its negative influence. The level of uncertainty was seen as unpresented, nothing like what companies had experienced previously: “Most companies have never seen such uncertainties we are facing in current times”, one manager claimed. This experienced uncertainty created a sense of urgency among the companies and they felt that traditional ways of organizing were not sufficient for managing it. As one team leader stated, "In $a$ complex and networked environment, cause and effect relationships disappear. Predicting outcomes becomes impossible”. When organisational members feel that their actions do not lead to planned 
and hoped-for outcomes, organisational practices need to reflect a sense of openness and ad hoc readiness.

The benefits of plural leadership relate to its processual nature. The author of the long narration, for instance, emphasized "learning from actions", "getting rid of long-term planning", and “experimenting” as crucial for dealing with unpredictability. All three practices emphasize managing unpredictability as on ongoing process in the moment. Another manager noted, "We are never done, though, and as we keep growing, we have to keep on improving our ways of working”. This suggests that established practices and routines are insufficient for facilitating constant change. In this context, plural leadership practices become associated with constantly improving and becoming better.

It also means that members of the organisation need to take even more responsibility for their actions. The threat of the unpredictable environment is relevant to everyone, as one manager noted: “Open and flexible organisational culture gives a lot to the individual employee. Yet, the challenging business environment demands that each member of the organisation is self-driven and carries their fair share of the responsibility. Power and responsibility are interrelated." In the plural leadership framework, power is not something that appears top-down, but it emerges throughout the organisation. All organisational members carry part of the responsibility in responding to an unpredictable and demanding environment.

\section{The development of new organisational roles: Breaking down hierarchies}

"When traditional organisations collide with a complex environment, the outcome might not be flattering. This, according to Stan McChrystal, happened to the US Special Forces fighting against al-Qaeda in 2003. The community of highly trained troops was constantly outsmarted by an enemy that was inferior in resources. Why? Because the enemy was highly decentralized 
and relied on a flat hierarchy, autonomy, speed, and a high level of adaptation. The Special Forces simply could not move fast enough. McChrystal came to realize that he had to abandon most of his ideas regarding managing efficient organisations, as well as what it meant to be a leader. Instead of increasing the amount of discipline, he started acting like-and I am quoting - 'a gardener'. This meant distributing decision-making power down to operators and intelligence officers, the people who did the actual work. McChrystal introduced extreme transparency by implementing a daily ninety-minute intelligence sharing session with over 7500 people. He started taking down silos by rotating personnel within different teams.”

Organisations that claim to follow the logic of plural leadership seek to transform organisational roles and make the distribution of power equal. The previous long narration, written by a manager, used the retired US Army General Stanley A. McChrystal as an example for how his organisation viewed roles, responsibilities, and tasks. The American General was described as “a gardener”; as a person, who made sure everyone, who were part of the mission, had the power to make decisions independently and through that independence, grow and become better.

Most often, this type of leaderless management approach means breaking down existing hierarchical structures, which can lead to a situation where it appears as though the differences between organisational roles, as we traditionally know them, disappear (for an account of rhizomatic organizing of a conflict in the case of Jihad, see Kuronen and Huhtinen, 2016). Accordingly, blog writers suggested that there is no difference between actors, who have power to make decisions, and actors, who act based on those decisions. As a team member noted, "In a flat organisation like ours, there is no distinction between those who make decisions and those who make stuff based on those decisions. It is the same people." According to a team leader, "Anything that advances the work of individuals or teams and makes it more productive is leadership.” This quote similarly suggests that 
there is no difference in roles, responsibilities, and decision-making as long as everyone is valuable and productive. Whatever helps the organisation is leadership.

While this was a common theme across the blogs we studied, there were also some notions, which suggested that having a flat organisation was not always easy. A new team member wrote about how difficult it was to adjust to a "leaderless" organisation: "Not being able to ask for permission or say 'my boss' creates uncertainty at first. People are so used to saying that. To realize that leadership can be shared takes a while.” Indeed, the transition from a traditional leadership structure to plural leadership can be a challenging one. It can also be stressful, because there is no single person who will say when work tasks are completed in a satisfactory manner. Rather, it is up to the individual worker to determine what reasonable expectations are and what it means to be a good employee.

In addition to feelings of uncertainty, the lack of a boss can lead to informal hierarchies that are difficult to detect. One team member recounted what it had been like to come to the organisation as a newcomer: "When I started working here, I did what people usually do, which is to recognize the hierarchy and identify the leaders through whom I can get my own voice heard. It is so challenging, perhaps there is no hidden hierarchy or perhaps each person has their own understanding of it." The writer sounded uncertain, maybe even paranoid, about whether there really was no formal hierarchy in the organisation. He also pointed out that what if each worker had his or her own understanding of how power was distributed. An unintended consequence of this can be that the organisation becomes a playground for different kinds of power games (see Spicer, 2018). When there is no formal power, people can begin to form coalitions, find allies, and manipulate decision-making. A team leader wrote about the need to get rid of individuals, who are not able to play by the new rules: 
"In the context of our organisational culture, which promotes positivity and equality, it is crucial to separate the good from the bad, whether we are dealing with a person who is a time thief, an antagonistic personality, or something like that. Most often, the situation is improved through assigning new work roles, training, or support from the team. There are cases, however, when it is better for everyone that such a person leaves the project."

To prevent this kind of negative experiences from happening, the organisations emphasized the importance of building a communal and trusting workplace culture.

\section{Community building through space and symbols}

"During the second world war, English Prime Minister Winston Churchill needed a place where he could 'direct the war'. Churchill and his team built war rooms under London where the core team met daily and the crucial information was available. The war room's walls were covered with important statistics, maps, and reports, and they were updated daily. A project room should be set up using the same principles. The room is simultaneously a workplace, meeting point, and knowledge center. Whiteboards or printed excel sheets are an easy way to hang the metric data. Be sure that your data is visible, clear, updated, and explained to everybody-also to the executive team."

In prior literature, plural leadership has been connected to materiality in organisations (Oborn et al., 2013; Raelin, 2016a; Ropo et al., 2015). In line with this, we found that the blog texts presented spaces and objects as to lead organisational actors and to generate a sense of community. Because of the intensity of work and the constant need to innovate, organisational spaces need to serve several purposes. As the manager who wrote the previous long narration said, “The room is simultaneously a workplace, meeting point, and knowledge centre”. As the organisational roles and routines change 
in plural leadership, spaces too have to function in different ways. They have to provide a setting for individual work, teamwork, and information sharing in a way that allows for shifting from one type of work task to another. In other words, the space needs to facilitate organisational workflow.

One team leader described the importance of organisational space more vividly: “The positive sense of urgency is really evident when the team arrives on Monday and immediately starts plastering postits onto walls like Jackson Pollock. The shared space is a visual display of the team's energy." Jackson Pollock was an American painter famous for his abstract art and style of drip painting. Just as Jackson Pollock used paint by pouring and dripping it on the canvas, the team members plastered post-its on the walls of the meeting room. This was a realization of the team's creative and collaborative energy.

Similarly to how organisational spaces can be used to promote teamwork and collaborative energy, material objects can create a sense of community and belonging (Edwards, 2011). In the previous example, post-it notes represent a material object that is used in community building. Everyone on the team could participate in the material activity of writing and posting the post-its. The creation process was a shared, rather than an individual, effort. Such materially shaped work practices—think of the whiteboards and the printed excel sheets from the long narration-did not only facilitate collaborative creative work, but also made work processes more visible across the organisation thus strengthening an understanding of community and shared goals.

Post-its, whiteboards, and printed excel sheets are concrete material aspects of the working environment. The objects around which the community building occurs can also be more symbolic, as the following example by a team leader suggests: "The history of the symbol is long. The story goes that even before the company was launched, someone became fascinated with this animal. More 
and more people started drawing it on whiteboards and decorate the office with little figures." The animal symbol this quote refers to is less related to the actual work practices and more associated with community building through its symbolic power. The symbolic power comes from the object's history and importance to the development of a shared organisational culture. The animal symbol has remained significant even though employees have changed and the organisation has evolved.

\section{Discussion and contribution}

In this study, we explored how plural leadership is narratively constructed in the online blogs of Finnish IT-companies. The knowledge-intensive business environment and the online data source provide an interesting context for studying what kind of practices are involved in plural leadership (Denis et al., 2012). In contrast to a noted limitation of the earlier studies that focus merely on leaders in formal roles (Bolden, 2011), our informants represented organisational positions at varied levels. Our analysis highlighted a narrative pattern of three categories that revealed practices associated with plural leadership. First, due to the dynamic nature of the business environment and the call for agile action, there was a concrete need to develop an organisational culture that was not leader-centric and hierarchical. In the organisations we studied, responding to an unpredictable environment was imperative for surviving and performing in IT-business.

Second, as the companies questioned the value of a hierarchical chain of command, they sought to adopt new organisational roles. As such, leadership responsibilities were shared and roles altered among a larger number of organisational members independent of their formal positions. Bolden (2011) noted that crossing organisational boundaries was an aspect of distributive leadership that scholars rarely study. Contractor et al. (2012) found that leadership roles, a dynamic notion of time, and relations between leaders and followers were key structural elements in collective leadership. 
Findings from our study make a unique contribution to this discussion, because these authors ignored the issue of breaking down organisational levels in an effort to promote the sharing of leadership.

Third, our analysis demonstrates that to be able to work in an unpredictable business environment with fluid leadership roles organisations need to pay attention to trust and community building. The cultural aspect of plural leadership was emphasized also by Cullen et al. (2012), who suggested three stages in the implementation of the DAC model of leadership (Direction, Alignment, and Commitment). The authors described a dependent culture that focuses on the formal leaders, an independent culture, where both the expertise and the formal positions build the culture, and interdependent culture, where "leadership is a collective activity of mutual inquiry and learning” (p. 429). Edwards (2011) drew on community research literature to develop a cultural perspective to distributive leadership. He considered a number of aspects, such as symbolism, sense of belonging, friendship, values, ethics (also Bolden, 2011), language, dialect, and discourse. While some of those aspects were present in our findings, we found the material spaces and objects to be particularly important for cultural community building.

To that end, our study develops a narrative framework that identifies the beginnings of a narrative logic behind plural leadership in knowledge-intensive organisations. Although being exploratory, the narrative pattern-responding to an unpredictable environment, new organisational roles, and community building — gives a plausible explanation to how organisational members at varied levels conceive and experience plural leadership. This narrative pattern provides a methodologically substantiated framework for studying plural leadership, which makes an important contribution to earlier studies that have focused on analytical elements concerning the phenomenon of plural leadership. 
A recent discussion on leadership-as-practice and plural leadership presented a number of limitations in prior research particularly from the critical perspective (Collinson, 2018). As noted by Bolden (2011), the plural and collective leadership literature has not addressed power and influence, asymmetrical hierarchies, structural inequalities, and diversities. We found that while managers described their firms as distributing power throughout the organisation, the team members wondered whether there were informal power structures that were difficult to detect. They did not specifically share negative experiences relating to this, but still reflected on whether genuine equality could exist among organisational members. Paradoxically, managers in a leader-centric manner offered employees the opportunity to engage in plural leadership, but the employees were not prepared to take on such a role. This raises the question, is plural leadership ultimately a form of ideological discourse that excludes language of power and hierarchy? In this scenario, the roles of leaders and followers, the core concepts of mainstream leadership research, would become insignificant. Offering a middle ground, Gronn (2010) suggested a conceptualization called "hybrid configurations of leadership”, where both hierarchical and peer relations could produce distributed leadership.

\section{Practical implications and future research}

Despite previous scholarly interest in the plural leadership phenomenon, it is still a relatively new leadership approach. Companies are only beginning to explore it and find ways to implement its ethos. The adoption of plural leadership practices can be transformative, because it requires that the organisations recognize a need for a new kind of organisational narrative. Developing such an understanding is time-consuming and demands attention and resources across the organisation.

Organisations that have implemented flat hierarchy and plural leadership can also be challenging workplaces. Professor André Spicer (2018) recently wrote a piece in The Guardian criticizing the “no bosses, no managers” -movement present across industries. He argued that flat hierarchies lead 
to favoritism and fear among the employees, when it is not clear whose rules matter the most. In line with our findings, we agree that there are tensions and power plays that can emerge in organisations. We argue, however, that in most organisations formal leadership positions have not completely disappeared. There are still CEOs and project managers, who have formal power in leading the company. It is imperative that these individuals pay attention to informal power plays that might develop in organisations that rely on flat hierarchies and plural leadership practices. Furthermore, organisations that choose to follow the logic of plural leadership should facilitate community building, which we found to be an important part of the narrative pattern.

While our exploratory study sheds light on the ways in which organisations and their leadership practices can be investigated using online data, we think that traditional organisational ethnographies would have a lot to give to this discussion. Findings on plural leadership can differ in important ways whether one observes leadership being produced online or in action in the workplace setting. Yet, our narrative pattern could provide a useful guide for future research relying on ethnographic observation.

\section{References}

Akemu, O. and Abdelnour, S. (2018), “Confronting the digital: Doing ethnography in modern organizational settings”, Organizational Research Methods, first published online August 20, 2018.

Avolio, B.J., Wakumbwa, F.O. and Weber, T.J. (2009), “Leadership: Current theories research and future directions”, Annual Review of Psychology Vol. 60, pp. 421-49.

Barad, K. (2003), “Posthumanist performativity: Toward an understanding of how matter comes to matter”, Signs: Journal of Women in Culture and Society, Vol. 28, No. 3, pp. 801-31.

Bolden, R. (2011), “Distributed leadership in organizations: A review of theory and research”, International Journal of Management Reviews, Vol. 13, pp. 251-269. 
Carlile, P.R., Nicolini, D., Langley, A. and Tsoukas, H. (Eds.) (2013), How Matter Matters: Objects, Artifacts, and Materiality in Organization Studies, Oxford University Press, Oxford.

Carroll, B. (2016), “Leadership as identity: A practice-based exploration”, in Raelin, J.A. (Ed.), Leadership-as-Practice. Theory and Application, Routledge, New York, NY and London, pp. 91-109.

Carroll, B., Levy, L. and Richmond, D. (2008), “Leadership as practice: Challenging the competency paradigm”, Leadership, Vol 4, pp. 363-79.

Collinson, M. (2018), “What’s new about leadership-as-practice?”, Leadership, Vol. 14, No. 3, pp. $363-370$.

Crevani, L. and Endrissat, N. (2016), “Mapping the leadership-as-practice terrain. Comparative elements”, in Raelin, J.A. (ed.), Leadership-as Practice. Theory and Application, Routledge, New York, NY and London, pp. 21-49.

Crevani, L., Lindgren, M. and Packendorff, J. (2007), "Shared leadership: A postheroic perspective on leadership as a collective construction”, International Journal of Leadership Studies, Vol. 3, No. 1, pp. 40-67.

Crevani, L., Lindgren, M. and Packendorff, J. (2010), "Leadership, not leaders: On the study of leadership as practices and interactions”, Scandinavian Journal of Management, Vol. 26, No.1, pp. 77-86.

Contractor, N.S., DeChurch, L. A., Carson, J., Carter, D.R. and Keegan, B. (2012), “The topology of collective leadership”, The Leadership Quarterly, Vol. 23, pp. 994-1011.

Cullen, K.L., Palus, C.J., Chrobot-Mason, D., and Appaneal, G. (2012), “Getting to "We”: Collective leadership development”, Industrial and Organizational Psychology, Vol. 5, No. 4, pp. 428432.

Dale, K. (2005), “Building a social materiality: Spatial and embodied politics in organizational control”, Organization, Vol. 12, No. 5. pp. 649-678. 
Denis, J.-L., Langley, A. and Rouleau, L. (2006), “The power of numbers in strategizing”, Strategic Organization, Vol. 4, No. 4, pp. 349-347.

Denis, J., Langley, A. and Sergi, V. (2012), “Leadership in the plural”, The Academy of Management Annals, Vol. 6, No.1, pp. 211-283.

Dourish, P. and Mazmanian, M. (2013), “Media as material: Information representations as material foundations for organizational practice”, in Carlile, P., Nicolini, D., Langley, A. and Tsoukas, H. (Eds.), How Matter Matters: Objects, Artifacts and Materiality in Organization Studies, Oxford University Press, Oxford, pp. 92-118.

Edwards, G. (2011), “Concepts of community: A framework for conceptualizing distributed leadership”, International Journal of Management Reviews, Vol. 13, 301-312.

Eslen-Ziya, H., and Erhart, I. (2015), “Toward post-heroic leadership: A case study of Gezi’s collaborating multiple leaders”, Leadership, Vol. 11, No. 4, pp. 471-488.

Fairhurst, G.T. and Grant, D. (2010), “The social construction of leadership: A sailing guide”, Management Communication Quarterly, Vol. 24, No. 2, pp. 171-210.

Glaser, B. and Strauss, A. (1967), The Discovery of Grounded Theory: Strategies for Qualitative Research, Wiedenfeld and Nicholson, London.

Gronn, P. (2002), “Distributed leadership as a unit of analysis”, Leadership Quarterly, Vol. 13, pp. 423-451.

Gronn, P. (2010), “Hybrid configurations of leadership”, in Bryman, A., Collinson, D., Grint, K., Jackson, B. and Uhl-Bien, M. (Eds.), Sage Handbook of Leadership, Sage, London, pp. 435452.

Hawkins, B. (2015), “Ship-shape: Materializing leadership in the British Royal Navy”, Human Relations, Vol. 68, No. 6, pp. 951-971.

Hosking, D.-M. (2007), "Not leaders, not followers: A post-modern discourse of leadership processes”, in Shamir, B., Pillai, R., Bligh, M. and Uhl-Bien, M. (Eds.), Follower-Centered 
Perspectives on Leadership: A Tribute to the Memory of James R. Meindl, Information Age Publishing, Greenwich, CT, pp. 243-263.

Humphreys, M. and Brown, A.D. (2002a), “Dress and identity: A Turkish case study”, Journal of Management Studies, Vol. 39, pp. 929-954.

Humphreys, M. and Brown, A.D. (2002b), "Narratives of organizational identity and identification:

A case study of hegemony and resistance”, Organization Studies, Vol. 23, 421-447.

Humphries, C. and Smith, A.C.T. (2014), “Talking objects: Towards a post-social research framework for exploring object narratives”, Organization, Vol. 21, No. 4, pp. 477-494.

Kempster, S., Parry, K. and Jackson, B. (2016), “Methodologies to discover and challenge leadershipas-practice”, in Raelin, J.A. (ed.), Leadership-as-Practice. Theory and Application, Routledge, New York, NY and London, pp. 242-261.

Kuronen, T. and Huhtinen, A.-M. (2016), “Organizing conflict: The rhizome of Jihad”, Journal of Management Inquiry, Vol. 26, No. 1, pp. 47-61.

Leonardi, P.M. and Vaast, E. (2017), “Social media and their affordances for organizing: A review and agenda for research”, The Academy of Management Annals, Vol. 11, No. 1, pp. 150-188.

Lin, K.-Y. and Liu, H.-P. (2011), “Intention to continue using Facebook fan pages from the perspective of social capital theory”, Cyberpsychology, Behavior, and Social Networking, Vol. 14, No. 10, pp. 565-570.

Lofland, J. and Lofland, L.H. (1995), Analyzing Social Settings. A Guide to Qualitative Observation and Analysis, Wadsworth Publishing Company, Belmont, CA.

Mabey, C. and Freeman, T. (2010), “Reflections on leadership and place”, in Collinge, C., Gibney, J. and Mabey, C. (Eds.), Leadership and Place, Routledge, New York, NY, pp. 139-156.

Margetts, H.Z., John, P., Hale, S.A. and Reissfelder, S. (2013), "Leadership without leaders? Starters and followers in online collective action”, Social Science Research Network. Available at: http://ssrn.com/abstract=2224187. 
Mart, S.M. (2011), “Alcohol marketing in the 21st century: New methods, old problems”, Substance Use \& Misuse, Vol. 46, No. 7, pp. 889-892.

McWhinney, W. (1984), “Alternative realities: Their impact on change and leadership”, Journal of Humanistic Psychology, Vol. 24, pp. 7-38.

Murthy, D. (2013), “Ethnographic research 2.0: The potentialities of emergent digital technologies for qualitative organizational research”, Journal of Organizational Ethnography, Vol. 2, No. 1, pp. 23-36.

Oborn, E., Barrett, M. and Dawson, S. (2013), “Distributed leadership in policy formulation: A sociomaterial perspective”, Organization Studies, Vol. 34, No. 2, pp. 253-276.

Orlikowski, W.J. (2007), “Sociomaterial practices: Exploring technology at work”, Organization Studies, Vol. 28, pp. 1435-1448.

Orlikowski, W.J. and Scott, S.V. (2008), "Sociomateriality: Challenging the separation of technology, work and organization”, The Academy of Management Annals, Vol. 2, No. 1, pp. 433-474.

Orr, J. (1995), Talking About Machines. An Ethnography of a Modern Job, Cornell University Press, Ithaca, NY.

Pearce, C.L., and Conger, J.A. (Eds.). (2003), Shared Leadership: Reframing the Hows and Whys of Leadership, Sage, Thousand Oaks, CA.

Powell, W.W., Horvath, A. and Brandtner, C. (2016), “Click and mortar: Organizations on the web”, Research in Organizational Behavior, Vol. 36, pp. 101-120.

Raelin, J.A. (2003), Creating Leaderful Organizations, Berrett-Koehler Publishers, San Francisco, CA.

Raelin, J.A. (2011), “From leadership-as-practice to leaderful practice”, Leadership, Vol. 7, No. 2, pp. 195-211.

Raelin, J.A. (2014), “Leadership-as-practice. A new movement in leadership”, Presentation at the 
Academy of Management Conference, 4 August, Philadelphia.

Raelin, J.A. (Ed.) (2016a), Leadership-as-Practice. Theory and Application, Routledge, New York, NY.

Raelin, J.A. (2016b), “It’s not about leaders: It's about the practice of leadership”, Organizational Dynamics, Vol. 45, pp. 124-131.

Riessman, C.K. (2008), Narrative Methods for the Human Sciences, Sage, Thousand Oaks, CA.

Ropo, A. and Salovaara, P. (2018), “Spacing leadership as an embodied and performative process”, Leadership, first published online April 16, 2018.

Ropo, A., Salovaara, P., Sauer, E. and De Paoli, D. (2015), Leadership in Spaces and Places, Edward Elgar, Cheltenham and Northampton, MA.

Ropo, A., Sauer, E. and Salovaara, P. (2013), "Embodiment of leadership through material place”, Leadership, Vol. 9, No. 3, pp. 378-395.

Sergi, V. (2016), “Who's leading the way? Investigating the contributions of materiality to leadership-as-practice”, in Raelin, J.A. (ed.), Leadership-as-Practice. Theory and Application, Routledge, New York, NY and London, pp. 110-131.

Slobin, A. and Cherkasky, T. (2010), “Ethnography in the age of analytics”, Ethnographic Praxis in Industry Conference Proceedings, Vol. 2010, No. 1, pp. 188-198.

Spicer, A. (2018), “No bosses, no managers: The truth behind the 'flat hierarchy' facade”, July 30, 2018, The Guardian.

Strauss, A.L. and Corbin, J.M. (1990), Basic of Qualitative Research: Grounded Theory Procedures and Techniques, Sage, Newbury Park, CA.

Sutherland, N., Land, C. and Böhm, S. (2014), “Anti-leader(ship) in social movement organizations: The case of autonomous grassroots groups”, Organization, Vol. 21, pp. 759-81.

Taylor, S. and Spicer, A. (2007), “Time for space: A narrative review of research on organizational spaces”, International Journal of Management Reviews, Vol. 9, No. 4, pp. 325-46. 
Uhl-Bien, M. (2006), "Relational leadership theory: Exploring the social process of leadership and organizing”, Leadership Quarterly, Vol. 17, pp. 654-676.

Van Marrewijk, A. and Yanow, D. (Eds.) (2010), Organizational Spaces Rematerializing the Workaday World, Edward Elgar, Cheltenham and Northampton, MA. 